\title{
Carbon nanotube formation using zeolite template and applications
}

\author{
Wei ZHAO, Bijay BASNET, Ik Jin KIM* \\ Institute for Processing and Application of Inorganic Materials (PAIM), Department \\ of Materials Science and Engineering, Hanseo University, Seosan city 356-706, Korea \\ Received September 14, 2012; Accepted September 27, 2012 \\ (C) The Author(s) 2012. This article is published with open access at Springerlink.com
}

\begin{abstract}
Carbon nanotubes (CNTs) have attracted intensive interests of researchers for a long time due to their fascinating physical and chemical properties promising for various potential applications, including advanced ceramics, nanoelectronic devices, nanoscale sensors, solar cells, battery electrode, field emitters, etc.. This review summarized the synthetic methods of CNTs, with an emphasis on the chemical vapor deposition (CVD) method, especially catalytic CVD. Although there still are some challenges in the way, with the development of the technology, a hope for widespread applications always exists.
\end{abstract}

Key words: carbon nanotubes; catalytic chemical vapor deposition; zeolite; template; catalyst

\section{Historical overview of carbon nanotubes}

The advent of green chemistry has significantly altered materials science and technology recently. For example, silicon ( $\mathrm{Si}$ ) has been known as the key material for electronic devices for a long time. In 1998, it became known that a particular form of carbon, namely carbon nanotubes (CNTs), can replace $\mathrm{Si}$ and lead to better electronic devices than those from $\mathrm{Si}$ [1]. This great excitement has promoted the intensive research over CNTs in the world.

Although CNTs have already been observed around the $17^{\text {th }}$ century [2], the credit for the discovery of CNTs is not obvious. An 1889 patent of Hughes and Chambers [3] filed to describe the technique of producing carbon filaments for glow discharge elements in lamps using methane and ethylene as carbon sources. Since the 1950 s, there have been lots

* Corresponding author.

E-mail: ijkim@hanseo.ac.kr of reports on observations of carbon filaments that could have been CNTs, while the technology of that time did not allow to clearly identifying them [4]. The "official" birthdate of CNTs is attributed to Dr. Sumio Iijima, who published an article [5] reporting the discovery of a "new type of finite carbon structure consisting of needle-like tubes" which comprises "coaxial tubes of graphitic sheets, ranging in number from 2 to about 50 ". To date, this article has been cited more than 10000 times as almost all papers regarding CNTs cited it.

Since then, progress on CNTs has evolved at a very high speed, starting with the discovery of single-walled CNTs (SWCNTs) and methods of producing them using transition metal catalysts by Bethune et al. [6] at IBM and Iijima and Ichihashi at NEC [7].

\section{Types of carbon nanotubes}

As known, carbon structures can exhibit multiple allotropic forms, with very disparate properties from 
the soft and conductive graphite to the hard and insulating diamond. The new carbon allotrope, fullerenes, also called "buckyballs" named after Richard Buckminster Fuller, is a closed cage composed entirely of carbon atoms tiling spherical or nearly spherical surfaces, the best known example being $\mathrm{C}_{60}$ with a truncated icosahedral structure formed by hexagonal and pentagonal rings, and can be assumed the form of a hollow sphere [8], as shown in Fig. 1a.

Another allotrope of carbon, CNTs, also known as tubular fullerenes, is rolled-up graphene sheets (Fig. 1b) of $\mathrm{sp}^{2}$-bonded carbon atoms. These nanotubes are concentric graphitic cylinders capped at either end by a half fullerene due to the presence of five-membered rings. They can be mainly classified into two types: single-walled CNTs (SWCNTs), and multi-walled CNTs (MWCNTs) with double-walled CNTs (DWCNTs) included [9], depending on the number of graphitic layers, as shown in Fig. 1c.

SWCNTs have a small diameter $(0.4-4 \mathrm{~nm})$ and exhibit the particular property that can be metallic or semiconducting, depending on their chirality [10]. On average, which means without chirality control, one third metallic and two thirds semiconducting SWCNTs can be obtained. A SWCNT is considered perfectly crystalline, i.e. defect-free, if the grapheme sheet has no variations in the hexagonal aromatic structure of the carbon atoms [11].

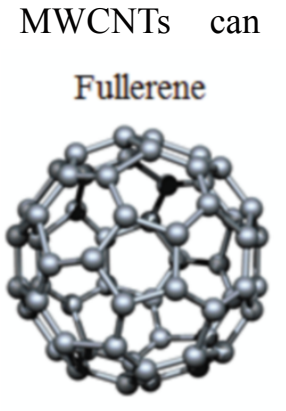

(a) be visualized as concentric
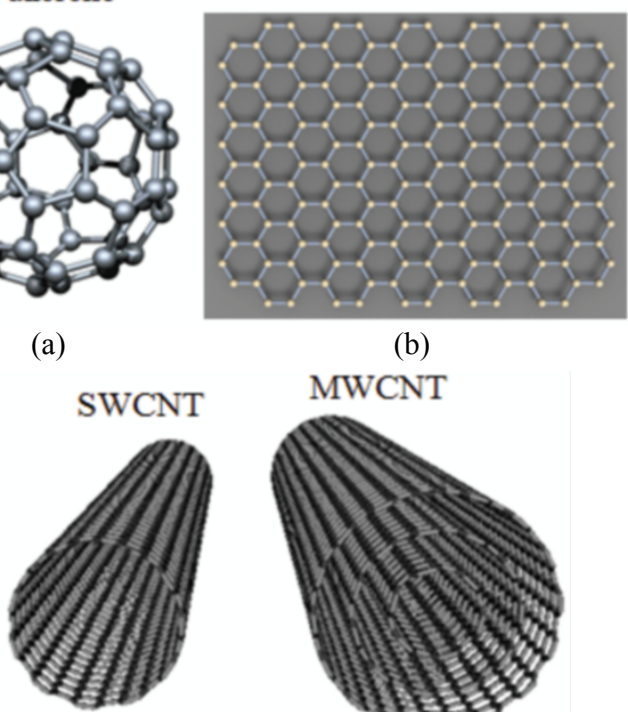

(b)

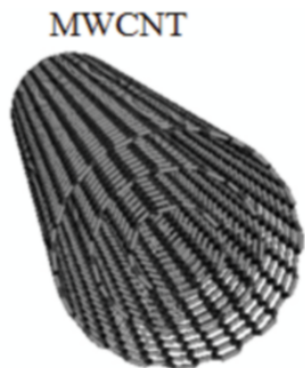

(c)

Fig. 1 Graphical representations of ideal (a) fullerene, (b) graphene, and (c) SWCNT and MWCNT (all cited from Google).
SWCNTs, which have a number of walls ranging from two to less than a hundred, leading to the diameter of a MWCNT ranging from $1 \mathrm{~nm}$ and rarely reaching beyond $100 \mathrm{~nm}$. In MWCNTs, the general intertube distance is $0.34 \mathrm{~nm}$, which is the same distance as that between two parallel graphene sheets in the graphite. Given the ratio of metallic to semiconducting being $1 / 3$ to $2 / 3$ for SWCNTs, it can be expected that MWCNTs are metallic in that at least one of the walls will be metallic. Some teams have been able to grow monochiral MWCNTs, indicating that all walls have the same chirality [12].

Ideally, crystalline SWCNTs and MWCNTs have walls and caps without any defects, i.e. missing or added atoms, which are extremely difficult to attain with our current synthesis techniques and to properly characterize. To date, some teams have grown individual or strands of CNTs with a length of a few centimeters [13].

\section{Properties of carbon nanotubes}

As mentioned before, only SWCNTs can be metallic or semiconducting depending on their chirality, thus SWCNTs have always been the focus of research due to their unique structures. The way the graphene sheet is wrapped is characterized by a pair of indices $(n, m)$ called the chiral vectors, where the integers $n$ and $m$ represent the number of unit vectors along two directions in the honeycomb crystal lattice of graphene [14], as shown in Fig. 2. Because of the varying degrees of twist of their rolled-up graphene sheets along the length, CNTs can have a variety of chiral structures. If $m=0$, the nanotubes are called "zigzag"; if $n=m$, the nanotubes are called "armchair"; otherwise, they are called "chiral". Also, when $(n-m)$ is a multiple of 3, the SWCNTs exhibit a metallic behavior (finite value of carriers in the density of states at the Fermi energy); and when $(n-m)$ is not a multiple of 3 , they are semiconducting (no charge carriers in the density of states at the Fermi energy).

Also depending on their diameter and the helicity of the arrangement of graphitic rings in the walls, they have been demonstrated to possess unusual electronic, photonic, magnetic, thermal, and mechanical properties. Due to their unique physical and chemical properties [15], they promise a variety of potential technological applications across many fields such as nanoelectronic devices [16] and interconnects [17], 


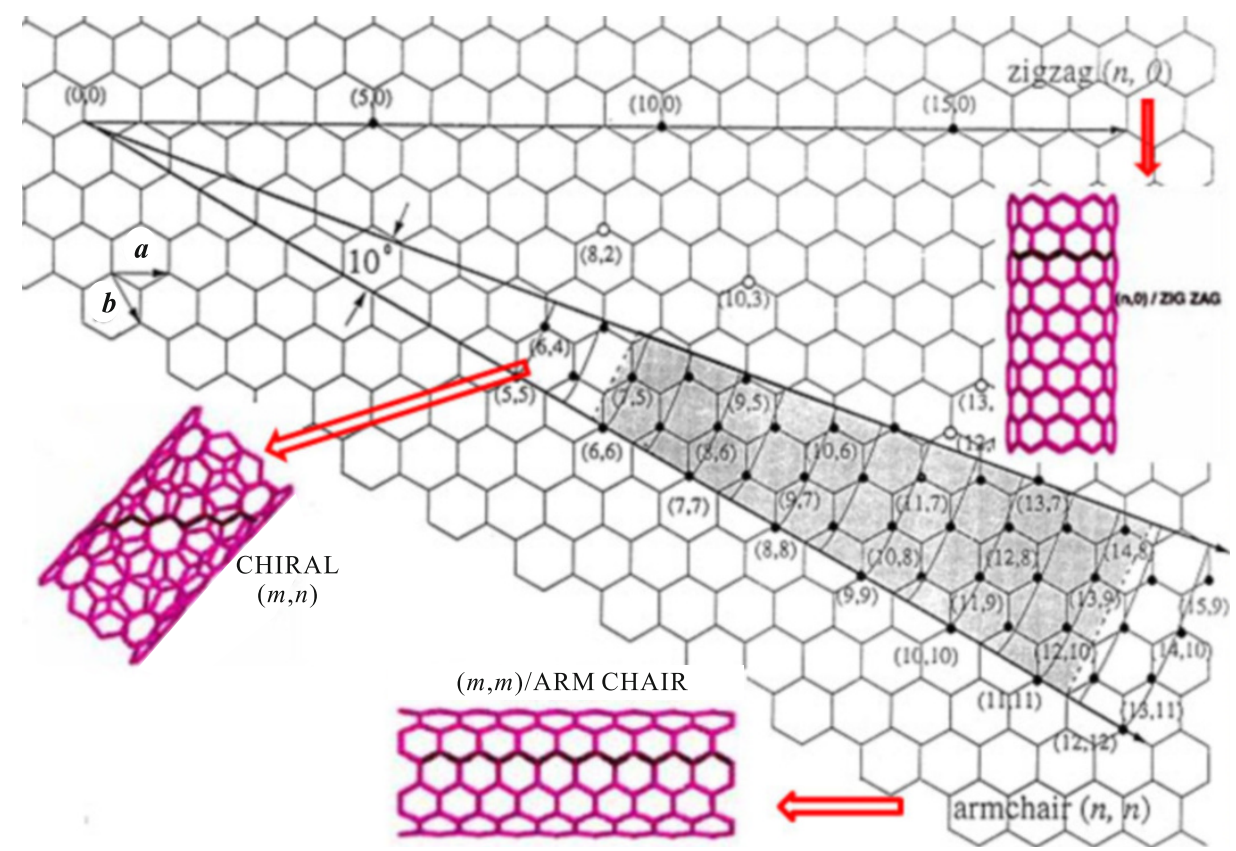

Fig. 2 Chirality $(\theta)$ of SWCNTs derived by rolling the Hamada vector $(c=n \boldsymbol{a}+m \boldsymbol{b})$ into a circle, with $\boldsymbol{a}$ and $\boldsymbol{b}$ being unit vectors of the graphene sheet constructed by carbon atoms in $\mathrm{sp}^{2}$ configuration.

sensors and actuators [18], energy storage media [19], and field emitters [20] et al.

\subsection{Electrical properties}

For graphene and SWCNTs, the electronic band structures are very similar. The valence band and the conduction band of graphene and metallic SWCNTs touch at specific points in the reciprocal space. While for semiconducting SWCNTs, they do not touch. Semiconducting SWCNTs have been extensively studied as channels in transistor devices (Fig. 3a) [21] while metallic SWCNTs have been considered for applications such as field emission [22] and IC interconnects (Fig. 3b) [23].

Theoretical studies have suggested that ideal CNTs are ballistic conductors for distances in the order of a micron [24]. The one-dimensional confinement of electrons combined with the requirements for energy and momentum conservation leads to ballistic conduction.

The electrical properties of SWCNTs have been studied intensively [25], often for the purpose of developing devices such as interconnect vias [26] or CNT-based transistors [27]. In contrast, the electrical properties of MWCNTs have not been investigated at the same level of details due to their additional complexities arising from the structure, as every shell has different electronic characteristics and chirality besides interactions between them [28]. However, for MWCNTs with both ends connected by metallic contacts, electronic transport is dominated by outer-shell conduction at low temperature and bias [29]. Theoretical models and experimental results point to the critical role of shell-to-shell interactions to

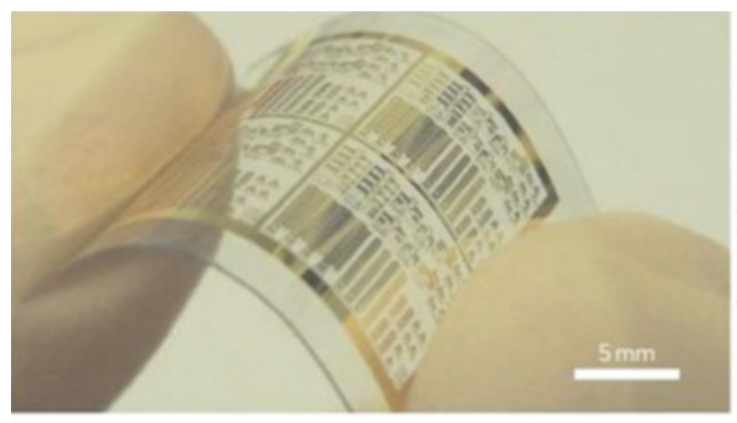

(a)

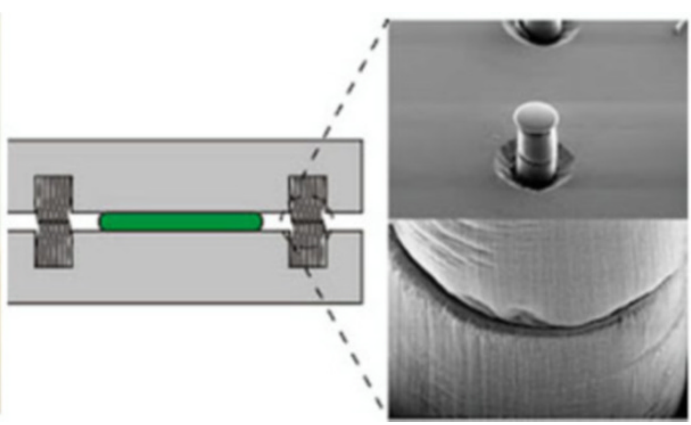

(b)

Fig. 3 (a) CNT thin-film transistors and integrated circuits on a flexible transparent substrate; (b) Two chips have interconnects that are filled with thousands of carbon nanotubes (both cited from Google). 
significantly lower the resistance of MWCNTs with a large number of walls [30,31].

\subsection{Mechanical properties}

It is indicated by theoretical calculations [32] and experimental results [33] that CNTs are stiffer than diamond, exhibiting the highest Young's modulus and tensile strength. Since CNTs are rolled-up graphene sheets, a first approximation for their elastic modulus would be that of graphene being approximately 1000 $\mathrm{GPa}$, five times that of steel. Many experiments have confirmed the theoretical predictions. For example, Yu et al. [34] measured the CNT tensile load using Atomic Force Microscopy (AFM) and found Young's modulus values ranging between $320 \mathrm{GPa}$ and $1470 \mathrm{GPa}$ (average $1002 \mathrm{GPa}$ ), which is consistent with the value estimated by Krishnan et al. [35] based on observations of SWCNTs freestanding room-temperature vibrations in a transmission electron microscope (TEM). Using first-principles calculations, Zhou et al. [36] estimated a Young's modulus of $760 \mathrm{GPa}$ and a tensile strength of 6.2 GPa for SWCNTs, while molecular dynamics studies by Yao et al. [37] led to values of 3.6 TPa for Young's modulus and of 9.6 GPa for tensile strength. Using TEM, Demczyk et al. [38] measured a Young's modulus of $0.9 \mathrm{TPa}( \pm 0.18)$ and a tensile strength of $150 \mathrm{GPa}( \pm 45)$, which are comparable to those of graphene sheets.

\subsection{Thermal properties}

Since graphite and diamond show exceptionally low heat capacity and high thermal conductivity, SWCNTs are expected to exhibit similar values for these properties and should converge to graphene at high temperature where the phonon quantization effects are not relevant. Intertube coupling in SWCNT ropes and intershell coupling in MWCNTs result in a low-temperature specific heat that resembles that of three-dimensional graphite [39].

The thermal properties of a suspended metallic SWCNT were extracted from high-bias (I-V) electrical characteristics achieved by Joule self-heating over the $300 \mathrm{~K}-800 \mathrm{~K}$ temperature range by Pop et al. [40]. They measured a thermal conductivity of almost $3500 \mathrm{Wm}^{-1} \mathrm{~K}^{-1}$ at room temperature for a $2.6 \mathrm{~mm}$ long SWCNT with a diameter of $1.7 \mathrm{~nm}$ and developed a model of thermal conductivity as a function of nanotube diameter and temperature. Similarly, Kim et al. [41] measured a thermal conductivity above
$3000 \mathrm{Wm}^{-1} \mathrm{~K}^{-1}$ at room temperature for MWCNTs using a microfabricated suspended device.

These high values for thermal conductivity constitute another useful property for electrical applications as thermal management and dissipation have become a very critical issue for downscaling the dimensions of future microprocessors.

\subsection{Field emission properties}

The property of field emission relates to the extraction of electrons from a solid material by tunneling through the surface potential barrier. The emitted current depends directly on the local electric field at the emitting surface and its work function. The Fowler-Nordheim model [42] shows an exponential dependence of the emitted current on the local electric field and the work function.

Given that the emitter shape (geometric field enhancement) and the chemical state of the surface have a strong impact on the emitted current, the small diameter and elongated shape of CNTs lead to a high geometrical field enhancement making them ideal candidates for field emission applications such as displays or triodes [43].

The principle of the field emission display has been schematically shown in Fig. 4.

\subsection{Photovoltaic devices}

Another promising field of CNTs is nanostructure-based solar cells [44]. The dispersion of CNTs in a solution of an electron donating conjugated polymer is perhaps the most common strategy to implement CNT materials into organic photovoltaic devices to obtain higher efficiency [45], as shown in Fig. 5. It has been reported that enhancements of more than two orders of magnitude have been observed in the photocurrent from adding the SWCNTs to the poly (3-octylthiophene) matrix [46]. As known, CNTs have a $1 \mathrm{D}$ and wire-like structure, making them better at forming electron- or hole-transporting high ways in the cell, and their large surface area enhances the separation of the electron-hole pair, leading to conductivity several times greater than that of conducting polymers. In these cells, they can act as both electron donors and acceptors depending on the redox properties of the other component. The use of CNTs in dye-sensitized solar cells has doubled the efficiency of this kind of photoelectrochemical solar cells [47]. 


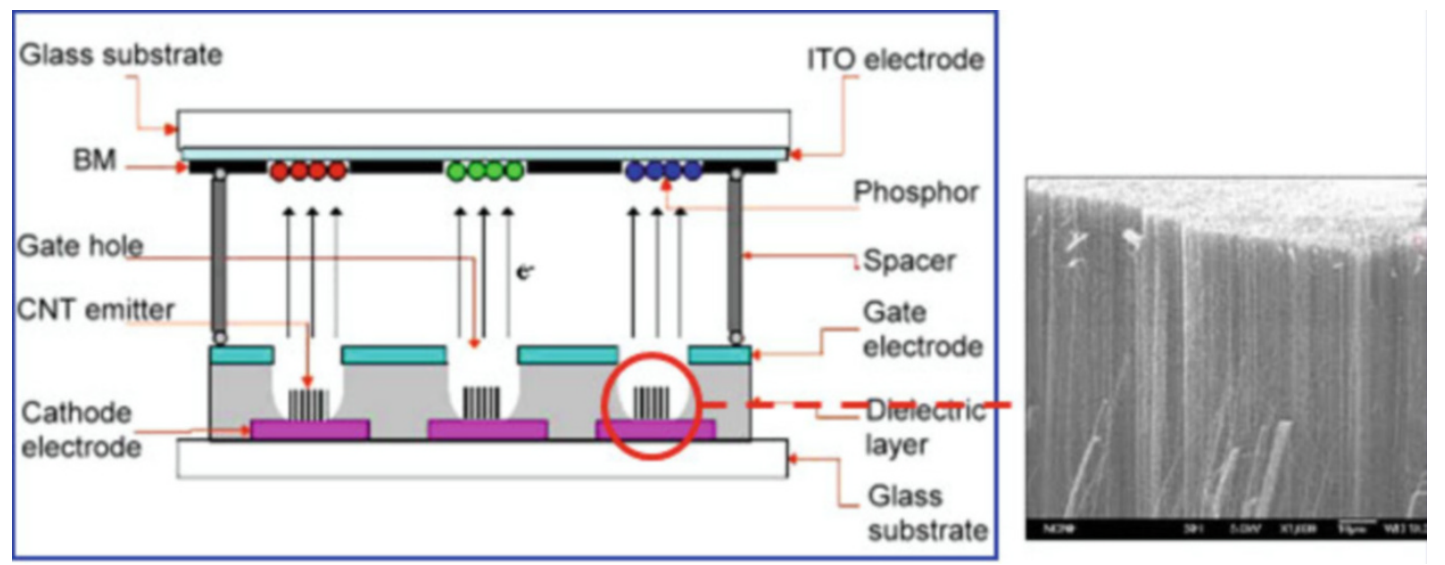

Fig. 4 Schematic of a field emission display (left) and SEM image of vertically-aligned CNTs (right) (both cited from Google).

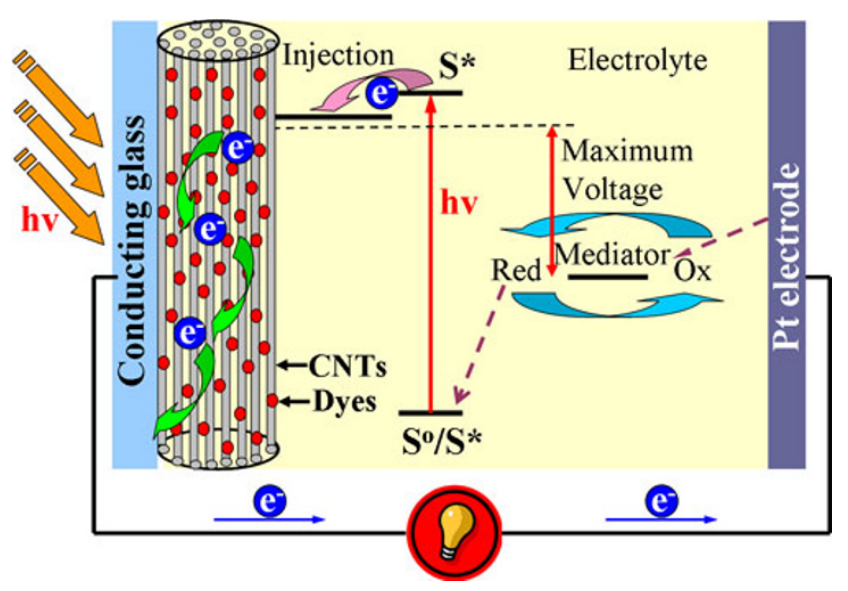

Fig. 5 Schematic diagram of CNT-based photovoltaic cell.

\section{Synthetic techniques of carbon nanotubes}

Since Iijima's discovery report [5] in 1991, CNTs have remained an exciting material ever. Their extraordinary properties mentioned above promoted a gold rush in academic and industrial groups all over the world to seek their practical uses. To date, thousands of publications and patents on innumerous potential applications of CNTs have been sprouted in almost all the aspects of our life, including media, entertainment, communication, transport health, environment and so on. Consequently, CNTs have become a material of common interest today; and society is eagerly looking forward to the charisma of them in household products. However, even after 20 years of continuous efforts, such products are still waitlisted.

The bottleneck is insufficient production and uncompetitive cost of CNTs with respect to the prevalent technology. Despite a huge progress in CNT research over the years, we are still incapable of producing CNTs of well-defined properties in large quantities with a cost-effective technique. The critical point of this problem is the lack of proper understanding of the CNT growth mechanism. To date, still no definitive model could be robustly established. There are several issues in the growth mechanism that are yet to be clarified. Ironically, the CNT researchers know how to make single-electron transistors from individual CNTs, but do not know how to make CNTs of the required structure. Hence it is necessary to retrospect. The skytower of the ambitious nanotechnology, especially the CNT-based technology, cannot be erected without a firm foundation of the growth-mechanism understanding.

There is a wide variety of fabrication techniques used to synthesize CNTs. Techniques such as arc discharge and laser ablation allow the synthesis of substrate-free CNTs with good crystallinity at high temperature. This brief section will introduce the most popular CNT fabrication methods to synthesize substrate-free CNTs.

\subsection{Electric-Arc discharge}

Arc discharge, a method developed by Kratschmer [48] and co-workers, was the first available method for producing both SWCNTs and MWCNTs. This technique has been used initially for fabricating carbon fibers and fullerenes, which may be the reason for CNTs not being characterized even if they were produced before 1991. For instance, Roger Bacon synthesized "thick" carbon whiskers in the early 1960s, as mentioned by Yakobson and Smalley [49]. One can 
imagine that he could have found CNTs in the soot if he had had a HRTEM.

In this method, CNTs are commonly prepared by striking an arc between graphite electrodes in an inert atmosphere (Ar or $\mathrm{He}$ ). If a catalyst is added to one of the electrodes, they can be easily obtained. The mechanism is based on energy transfer between the target materials, graphite, which is kept at temperatures close to its melting point and an external radiation source, as shown in the Fig. 4 by Nessim [11]. The apparatus of the method is shown in Fig. 6.

The technique has a major advantage, that it is possible to produce CNTs with a good crystallinity by tuning the parameters, which leads to their superior electrical and mechanical properties. This may be caused by the high temperature where the process operates, even higher compared to CVD. Its major drawback is that, CNT products have to be separated from other carbon products and catalyst residue.

\subsection{Laser ablation}

This method was first demonstrated by Smalley's group [50], which as well has been used for the generation of fullerene clusters. The principles and mechanisms are similar to the arc discharge. Their only difference is that the energy in the method is provided by a laser striking a graphite pellet containing catalyst materials (usually Ni or Co). The laser, which can be operating in pulsed mode or in continuous mode, vaporizes the carbon and the catalyst metal. The vaporized species are then directed to a water-cooled copper collector by a flow of neutral gas where they condense, as shown in Fig. 7.

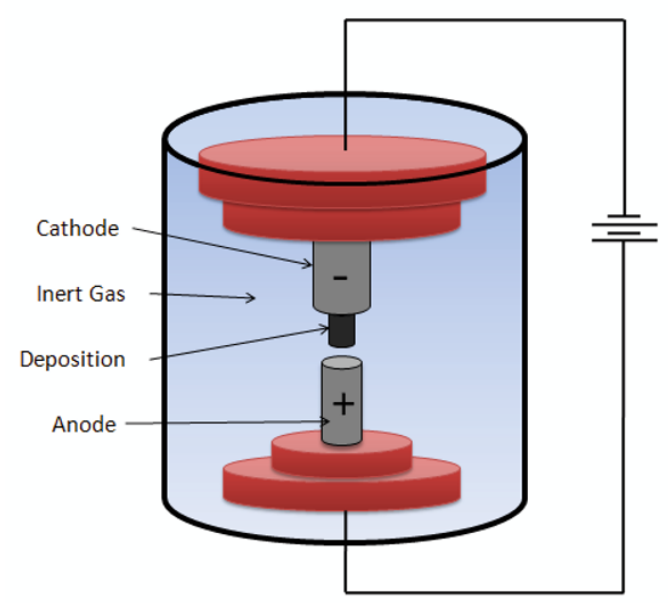

Fig. 6 Schematic diagram of electric-arc discharge apparatus.

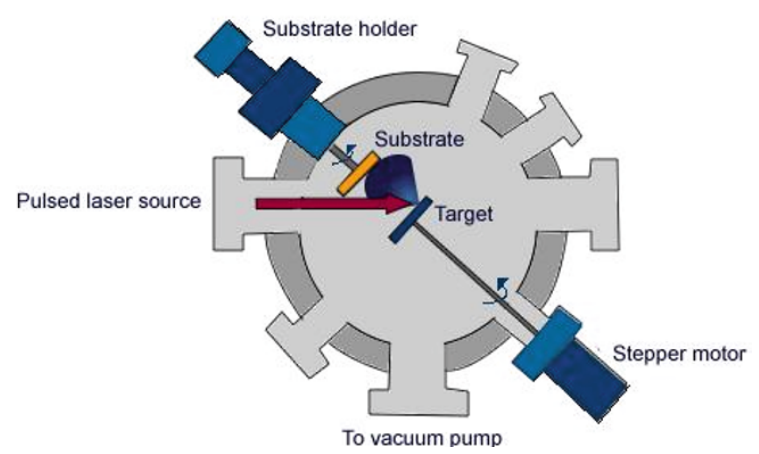

Fig. 7 Schematic diagram of laser ablation apparatus.

Using this method, we can collect MWCNTs in the soot with diameter of $1.5 \mathrm{~nm}$ to $3.5 \mathrm{~nm}$ and with length around $300 \mathrm{~nm}$ [11]. CNT crystallinity is a function of the furnace temperature $\left(1200{ }^{\circ} \mathrm{C}\right.$ is optimal for best quality CNTs). By introducing small quantities of metal catalyst in the pellet, SWCNTs with good crystallinity can be obtained.

Unfortunately, this technique is not economically advantageous because the process involves high-purity graphite rods, the laser powers required are high (in some cases two laser beams are required), and the amount of CNTs that can be produced per day is not as high as arc discharge method.

\subsection{Chemical vapor deposition (CVD)}

Chemical vapor deposition (CVD) is one of the most popular thin film deposition methods. It is very different from the other two common methods mentioned above for CNT production. Nowadays, it has become a most popular and widely used technique because of its low set-up cost, simple operating conditions, easy control of experimental parameters, high production yield, and ease of scale-up. Some CVD methods have been reported, such as thermal CVD, plasma-enhanced CVD, and catalytic pyrolysis of hydrocarbon, i.e. catalytic CVD (CCVD), which is most frequently employed [51,52] and offers great advantages over other techniques, where CNTs are grown over catalysts containing nanoparticles of transition metals $(\mathrm{Fe}, \mathrm{Co}, \mathrm{Ni})$ or related oxides by the decomposition of a carbon source (e.g., $\mathrm{CH}_{4}, \mathrm{C}_{2} \mathrm{H}_{2}$, etc.). The equipment we used is shown in Fig. 8.

Earlier, most CVD-grown CNTs were "spaghettilike" and defective, but the potential of the technique to satisfy technological requirements was recognized. Since 1998 onward, substantial and rapid progress has been made in the development of CVD to establish it 


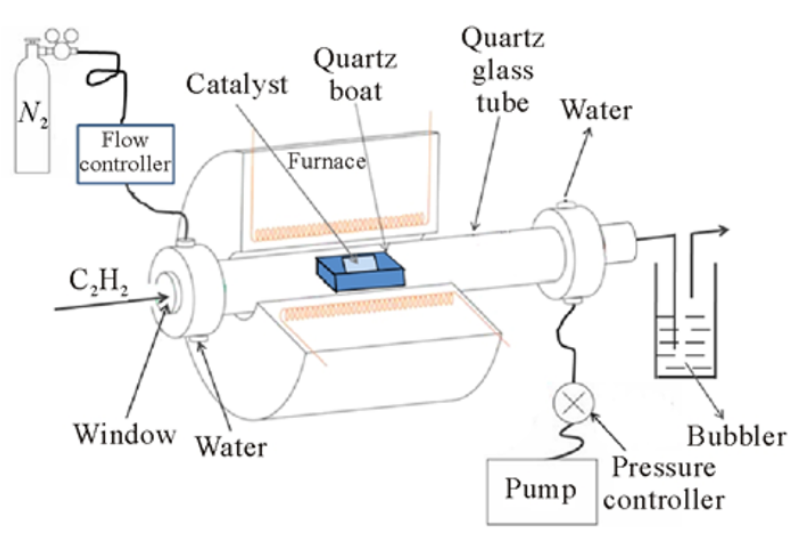

Fig. 8 Schematic image of CNT production by CCVD.

as a highly controlled technology for producing CNTs. To date, it is possible to fabricate high-quality SWCNTs and MWCNTs in bulk or directly onto substrates as a raw material $[53,54]$. In addition, it can be integrated as a step in chip fabrication and, by appropriate patterning, can be used to synthesize CNTs in desired locations on substrates, although a complete understanding of the growth mechanism of CNTs is still unclear at this time.

\section{Main focuses of CNT researchers}

As mentioned, only SWCNTs can be metallic or semiconducting depending on their chirality. The combination of hollow structure, small diameter, and high aspect ratio make them unusual 1D (onedimensional) materials with a very low mass density [55] and an extremely high specific surface area [56]. Moreover, the strong C-C covalent bond in the lattice along the tube axis, and the closed fullerene caps endow SWCNTs with remarkable properties, such as good electrical [57] and thermal [58] conductivity, chemical [59] and thermal [60] stability, unique electronic properties [61] and so on, thus controlling the diameter, chirality together with high-purity has always been one focus of research.

In addition, for the sake of various nanodevices, it is extremely important to assemble SWCNTs on desired surface and precise locations with controlled density and orientation. The high order of their alignments can improve the performance of many CNT-based devices. For instance, the well-known field emitters in panel display have a high requirement for vertically aligned CNTs (VACNTs) [62], because it was found that aligned arrays of CNTs were superior to the unaligned CNT films for developing emitters with high operating currents at low driving voltages [62]. It has also been demonstrated that VASWCNTs were excellent field emitters with an operating field much lower than those of traditional film emitters [63]. Therefore, controlling the orientation of CNTs is undoubtedly another focus of research.

\section{Synthesis of CNTs using templates}

In principle, finely dispersed, nanometer-sized metal particle catalysts that preserve their morphology at the CVD processing temperatures are required because controlling the morphology of the catalytic particles during CNT growth strongly affects nanotube characteristics such as thickness, uniformity, and yield. However, as the size of the metal particles decreases to the nanometer scale, they tend to agglomerate. To prevent this, porous materials have been proposed as supports. A porous support exhibiting a non-continuous surface and high surface area can not only contribute significantly to particle stabilization and produce a fine dispersion of well-defined particles, but also drastically increase the number of catalytic particles, thus increasing the number of nucleation sites, which are all advantageous to the synthesis of CNTs [64]. Commonly used substrates in CVD include silicon [65], quartz [66], silica [67], silicon carbide [68], alumina [69], aluminosilicate (namely, zeolite) [70,71], magnesium oxide [72], and etc. Among all the catalytic supports, zeolites being molecular sieve materials with pore diameters in the range of $3 \AA$ - $10 \AA$ have had a significant impact due to their structural homogeneity, and high reactive surface area, which makes them excellent host candidates for different types of adsorbing molecules [73] and hence zeolites could be used as supports for catalyst particles to synthesize and grow CNTs.

In this review, the zeolite (FAU) was used as the template for supporting catalyst nanoparticles to synthesize CNTs via the CCVD method. Through testing and analysis of the results, the influence of different iron contents supported in the zeolite, and the effect of the catalyst content on the support and the reaction time on the synthesis and growth of CNTs were investigated.

\subsection{Zeolite templates}

From Table 1, it is obvious to see that well-controlled zeolite crystals with different shapes and size can be obtained with different initial compositions, i.e., molar ratios of $\mathrm{TEOS} / \mathrm{Al}$ (i-pro) ${ }_{3}$. 
Table 1 Zeolite products synthesized with different molar ratio of TEOS /Al(i-pro) $)_{3}$.

\begin{tabular}{|c|c|c|c|c|c|c|}
\hline $\begin{array}{c}\text { TEOS/ } \\
\mathrm{Al}(\text { i-pro })_{3}\end{array}$ & Frame-work & Material & $\begin{array}{c}\text { Cubic str. } \\
\text { Lattice constant }\end{array}$ & Crystal Morphology & Pore Dimension & $\begin{array}{c}\text { Particle size by } \\
\text { TEM }\end{array}$ \\
\hline 2.2 & LTA & $\mathrm{NaA}$ & $\begin{array}{c}\operatorname{Pm} 3 \mathrm{~m} \\
a=12.157 \AA\end{array}$ & Cube-Octaherdron & $4 \AA$ & $264 \mathrm{~nm}$ \\
\hline 3.2 & LTA+FAU & NaA-NaY, (5\%) & $\begin{array}{c}\mathrm{Pm} 3 \mathrm{~m} \\
a=12.157 \AA \\
\mathrm{Fd}-3 \mathrm{~m} \\
a=24 \AA\end{array}$ & Cube + Octaherdron & $4 \AA+7-8 \AA$ & $200-400 \mathrm{~nm}$ \\
\hline 4.2 & FAU & $\mathrm{NaY}$ & $\begin{array}{l}\mathrm{Fd}-3 \mathrm{~m} \\
a=24 \AA\end{array}$ & Octaherdron & $7-8 \AA$ & $150-30 \mathrm{~nm}$ \\
\hline 5.2 & SOD & $\begin{array}{c}\text { Sodalite } \\
\text { Octahydrate, } 100 \%\end{array}$ & $\begin{array}{c}\operatorname{Im} 3 \mathrm{~m} \\
a=8.975 \AA\end{array}$ & Octaherdron & $\begin{array}{l}\text { Space filling } \\
\text { structure }\end{array}$ & $30-50 \mathrm{~nm}$ \\
\hline
\end{tabular}

Figures. 9a, 9b and 9c show the SEM and TEM image of the well-formed $\mathrm{NaX}$ zeolite crystal and its schematic structure, respectively. Figures $9 \mathrm{a}$ and $9 \mathrm{~b}$ reveals a high degree of structural order in the crystal surface formed inside the complementary pores between two distinct peaks, each centered at $13.942 \AA$, corresponding to the inner diameter of the zeolite
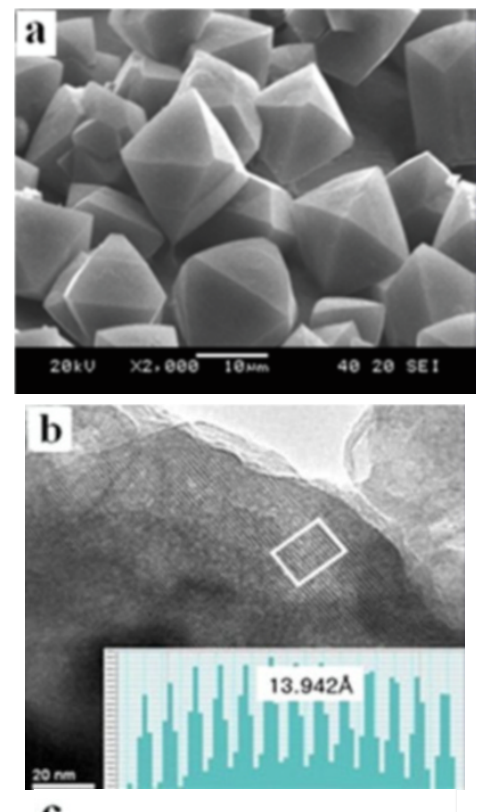

C

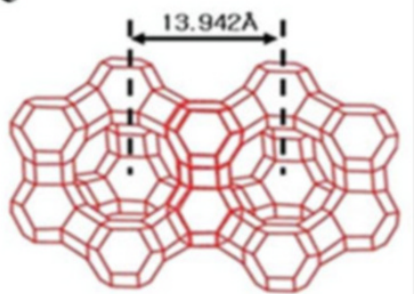

Fig. 9 (a) SEM image of synthesized NaX crystals, (b) TEM image of the NaX crystal, (c) the schematic structure of the NaX crystal. structure. As shown in Fig. 9c, NaX zeolite can be described as an ensemble of sodalite cages or ß-cages joined hexagonal prisms. Generally, this structure can be envisaged as a stack of layers of sodalite cages joined by double six rings (D6R) in a tetrahedral arrangement like the carbon atom in diamond, with a center of inversion at the center of the D6R. The $B$-cage is surrounded by an even larger cage, the supercage (a cavity with a diameter of about $13 \AA$ ), which forms a three-dimensional network with each cage connected tetrahedrally to four other supercages through the 12-membered ring opening with a crystallographic aperture of $7 \AA-8 \AA$ [74]. This nano-structured zeolite material was applied as the host material for holding catalyst nanoparticles in order to synthesize CNTs $[47,75]$.

\subsection{Metal-supported zeolite}

In order to take advantage of the porous structure of zeolite, metal-supported zeolite was prepared with a conventional and simple ion-exchanging method in the aqueous solution. The ion-exchange between metal ions and the zeolite $(\mathrm{NaX})$ is simply shown in Fig. 10.

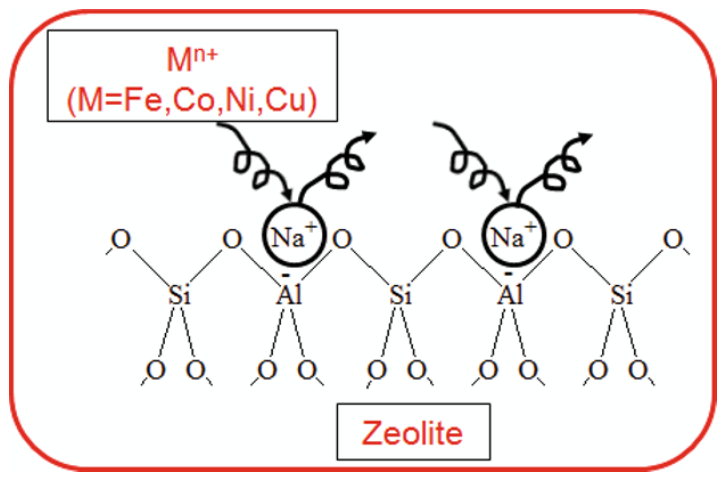

Fig. 10 Schematic mechanism of the ion-exchange between metal ions and $\mathrm{NaX}$. 
The morphological characteristics of the metal-supported zeolite powder were investigated by TEM, as shown in Fig. 11(a-d, upper row). FeNaX clearly revealed a random dispersion of Fe-containing catalyst particles in the zeolite, while CoNaX had a relatively regular arrangement of Co-containing particles, even it is hard to confirm that there is no agglomeration at all. Despite that, the CoNaX sample definitely exhibited less agglomeration than FeNaX. Moreover, the zeolitic structure of the FeNaX had been severely ruptured while that of the CoNaX mostly retained its original morphology, which has been identified by their XRD patterns (not shown here). As shown in Fig. 11(c-d, upper row), however, both $\mathrm{NiNaX}$ and $\mathrm{CuNaX}$ exhibited homogeneous dispersion of fine catalyst particles in the zeolite, despite their different morphologies, the former presenting in a corncob-like shape and the latter as a nut with a kernel. In addition, it should be noted that an irregular zeolitic structure might be presented after the calcination of all metal-supported zeolites, indicating that the zeolite crystals had been ruptured and contained irregularly shaped cavities with a size distribution in the range of mesopores. This implied that ion-exchanging led the $\mathrm{Ni}^{2+}$ and $\mathrm{Cu}^{2+}$ cations to much more homogeneous dispersing in the zeolite compared to the $\mathrm{Fe}^{2+}$ and $\mathrm{Co}^{2+}$ cations, which had greater aggregation tendencies.

\subsection{Formation of carbon nanotubes by CCVD}

The CNTs were synthesized by catalytic decomposition of acetylene $\left(\mathrm{C}_{2} \mathrm{H}_{2}\right)$ in a fixed-bed flow reactor as shown in Fig. 8. The reactor setup consists of a quartz boat containing the catalyst samples which were placed in a horizontal electric tubular furnace. The certain process has been described in detail in our former work $[47,76]$.

\subsubsection{Impact of metal species}

As shown in Fig. 11(a-d, lower row), the CNT-FeNaX and CNT-CoNaX samples clearly exhibited precise MWNTs. However, the former had more defects such as amorphous carbon and disordered graphene layers, indicated by arrows on the left side and right side, respectively, of the image shown in the inset of Fig. 11(a, lower row). The latter had less amorphous carbon and a much higher crystallinity, even though a few disordered graphene layers were observed on the outer layer of CNTs, shown by the arrow in the inset of Fig. 11(b, lower row). Moreover, the latter exhibited more uniform-sized products than the former. However, the CNT-NiNaX and CNT-CuNaX samples clearly exhibited some obvious forms of synthesized graphitic materials other than CNTs. As seen in the upper inset of Fig. 11(c, lower row), some quasi-CNTs were found in the CNT-NiNaX sample in coexistence with the CNTs. These CNTs were termed "quasi" because the products presented a clear inner tube with no outer graphene layers that were formed as the CNT walls, but rather belt-shaped outer layers were observed and these were similar to the shape of the carbon nanofibers (CNFs), as shown in the lower inset in Fig. 11(c, lower row). This phenomenon indicates that well-dispersed, Ni-containing catalyst particles formed belt-like or other non-isotropic structures in our work, which is slightly different from the result of a former

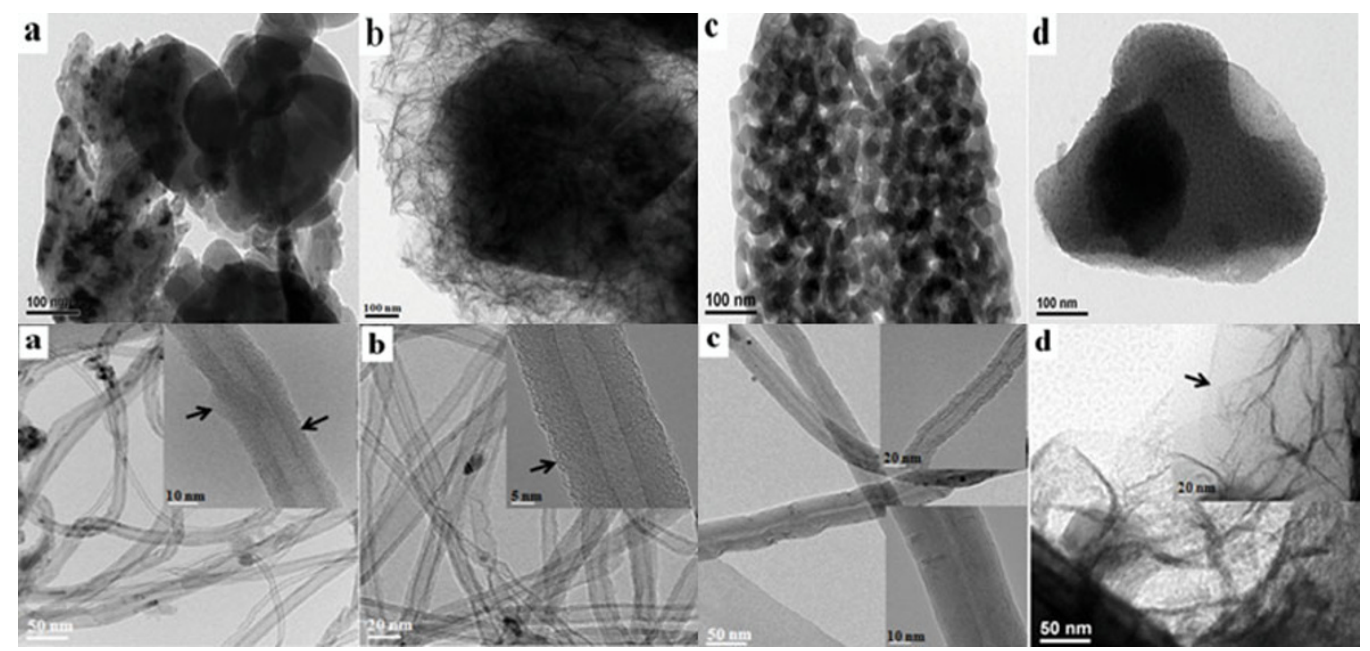

Fig. 11 TEM images of metal-supported zeolite powder (upper row): (a) Fe-NaX, (b) Co-NaX, (c) Ni-NaX, and (d) $\mathrm{Cu}-\mathrm{NaX}$; CNTs synthesized from different metal-supported zeolite (lower row): (a) CNT-FeNaX, (b) CNT-CoNaX, (c) CNT-NiNaX, and (d) CNT-CuNaX. 
study [77]. Additionally, the products shown in Fig. 11(d, lower row) seemed different from CNTs or CNFs. Due to their transparent feature and dark vein-like structure indicated by the arrow (the inset of Fig. 11(d, lower row)), it was reasonable to consider them stacks of graphene sheets that contained curving edges. It was suggested that the CNTs formed on the outer surface of the zeolite, since ultra-thin-layer nanotubes could penetrate the nano-pore openings of zeolite [78]. It was also suggested that possible coke formation during the initial steps of the acetylene decomposition resulted in blockage of the pores that hindered further transport of the reactants to the active metal sites inside the zeolitic micropores [79].

\subsubsection{Effect of metal content and reaction time}

Given the main CNT product synthesized from $\mathrm{FeNaX}$ and $\mathrm{CoNaX}$, they were focused on investigating the effects of parameters, i.e. metal content and reaction time.

All synthesized CNTs using zeolite template clearly are MWNTs. Through a comparison between the EDX data of $\mathrm{FeNaX}$ and $\mathrm{CoNaX}$ [76], it is clear that $\mathrm{Co}^{2+}$ ions are completely exchanged, whereas not all $\mathrm{Fe}^{2+}$ ions were exchanged resulting in some residual $\mathrm{Na}^{+}$ ions. Therefore, it is inferred that $\mathrm{Co}$ is more favorable for complete ion-exchange than Fe. Also, CNTs could be synthesized at a low metal content, especially $\mathrm{Fe}$, and exhibited a growth (including length and yield) tendency with increasing metal content. This suggests that more catalyst particles act as "seeds" for the CNT synthesis with increasing metal content, leading to the increasing CNT yield, which can obviously be obtained from the data shown in Table 2.

In the meanwhile, according to our previous work [76], with increasing $\mathrm{Fe}$ content, CNTs from Fe-supported zeolite exhibited an irregularly distinct variation of their inner diameters. This may indicate that catalyst nanoparticles in the Fe-supported zeolite are randomly dispersed and tend to agglomerate intensively during the synthesis, leading to an increased diameter and greater number of walls. In contrast, the relatively homogeneous distribution of Co species more readily leads to the formation of CNTs with less distinctness, which is in accordance with the generally accepted theory holding that the diameter of CNTs is determined by the catalyst particle size [80]. In addition, an interesting result was that SWCNTs can be synthesized from Co-supported zeolite with increasing Co content, which was shown in Fig. 12 [81]. According to the relationship between the diameter $(d)$ and the frequency $(\omega)$ :

$$
\omega_{\mathrm{RBM}}=224 / d+10[\mathrm{~nm}]
$$

the Raman peak at $121 \mathrm{~cm}^{-1}$ corresponds to diameter of $2.0 \mathrm{~nm}$.

Following, the effect of synthesizing time on CNT products was also investigated, as shown in Fig. 13 [82]. Taking FeNaX group catalyst as an example, it is easy to find that with increasing reaction time their inner diameters are close to $10 \mathrm{~nm}$ without distinct changes. However, their outer diameters have a monotonic increase with prolonging reaction time, which corresponds to the increasing number of layers of CNT walls. This result reveals that carbon atoms

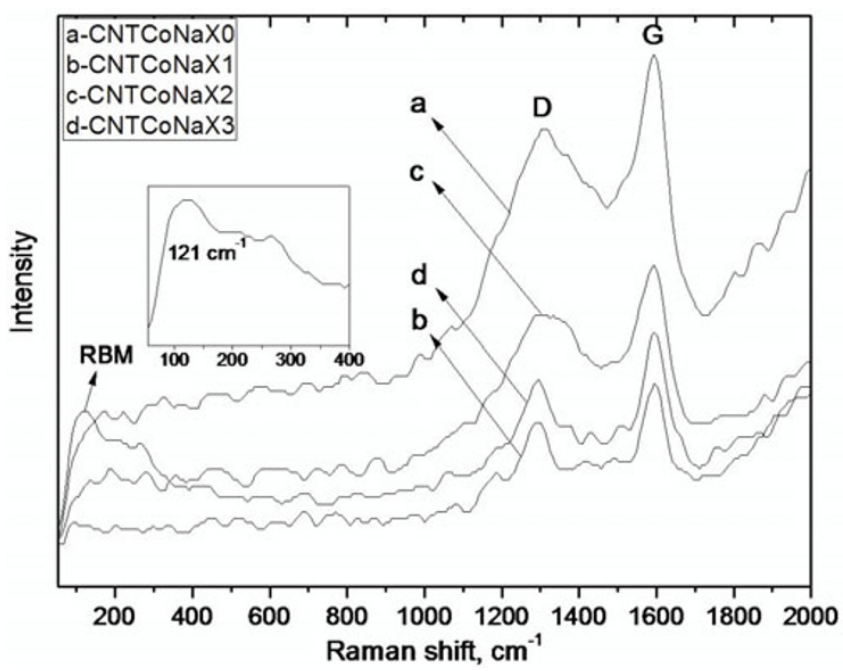

Fig. 12 Raman spectra of synthesized CNTs from Co-supported zeolite: (a) CNT-CoNaX0, (b) CNT-CoNaX1, (c) CNT-CoNaX2, and (d) CNT-CoNaX3.

Table 2 Carbon yield (TGA) and quality (Raman spectroscopy) of the CNTs synthesized with zeolite supported by different iron and cobalt contents.

\begin{tabular}{cccccc}
\hline \multirow{2}{*}{$\begin{array}{c}\text { Sample } \\
\text { code }\end{array}$} & \multirow{2}{*}{ Metal content, mol\% } & \multicolumn{2}{c}{ Carbon yield \% } & \multicolumn{2}{c}{ Raman ratio $\left(I_{\mathrm{D}} / I_{\mathrm{G}}\right)$} \\
\cline { 3 - 6 } & & CNT-FeNaX & CNT-CoNaX & CNT-FeNaX & CNT-CoNaX \\
\hline 0 & 0.04 & 37.1 & 36.0 & 0.89 & 0.85 \\
1 & 0.08 & 43.2 & 39.5 & 0.83 & 0.76 \\
2 & 0.12 & 52.9 & 63.7 & 1.20 & 0.83 \\
\hline
\end{tabular}




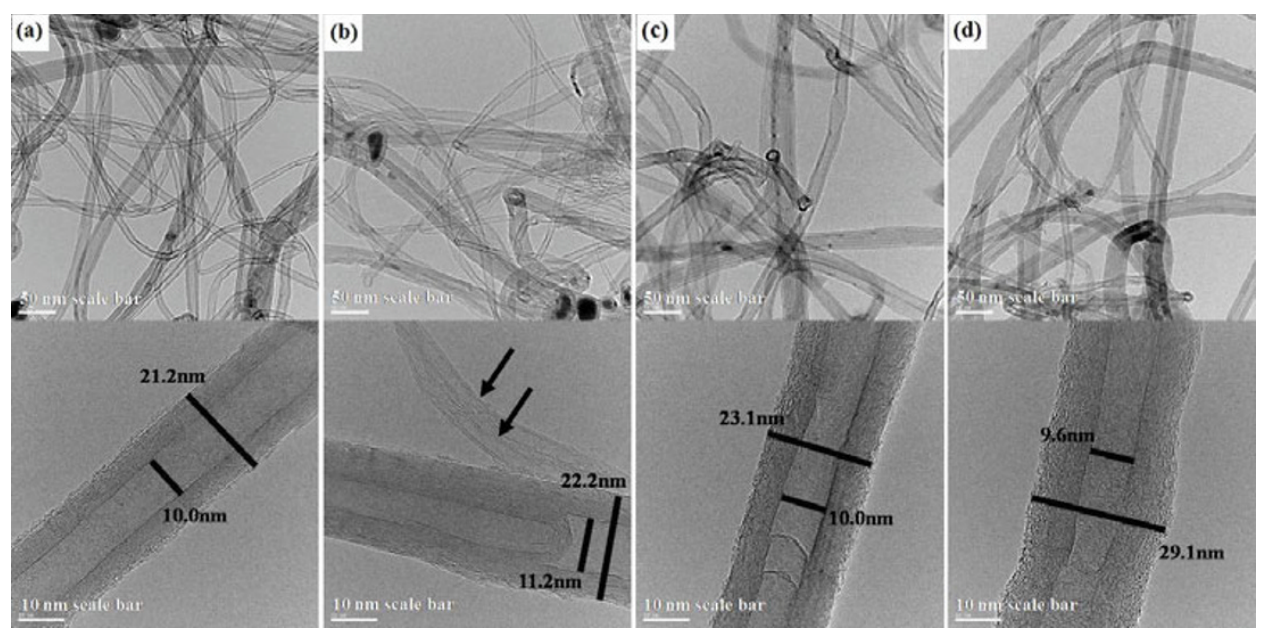

Fig. 13 TEM images of CNTs synthesized from Fe-supported zeolitefor different reaction time: (a) CNT30, (b) CNT60, (c) CNT120, and (d) CNT180.

decomposed from $\mathrm{C}_{2} \mathrm{H}_{2}$ form coaxial cylindrical graphene sheets layer by layer around the core of CNTs with a prolonging reaction time.

\subsubsection{Mechanism of carbon nanotube synthesis and growth}

Historically, the most accepted growth model is the vapor-solid-solid (VSS) model which derives from the vapor-liquid-solid (VLS) model originally suggested by Wagner and Ellics [83] for the growth of silicon whiskers. Using the VSS model, the excess carbon from the decomposition of the hydrocarbon gases precipitates on the surface of the catalyst, diffuses into the catalyst, and nucleates the CNTs at the edges of the catalyst.

Figure 14 shows CNT synthesis mechanisms as well as typical TEM images for them. Some isolated CNTs (Fig. 14a) point to the so-called base-growth model, while some of them (Fig. 14b) point to the tip-growth model of CNTs in our CCVD process $[84,85]$. Meanwhile, due to the powder state of the catalysts used in our study, combined with the existing base- and tip-growth models, CNTs can be grown from catalyst particles along both directions at the same time, the schematic of which is shown in Fig. 14c. Until now, the growth mechanism shown in Fig. $14 \mathrm{c}$ is still unclear to us. However, there is another possibility that due to the morphology and state change of the catalyst nanoparticles during the growth, they can be any location inside the CNTs. This has been reported by others [86].

Apart from the result we observed, the growth mechanism of CNTs is still not clearly understood although extensive experimental and theoretical studies, and more recently, in situ HRTEM have provided numerous hints on the possible mechanisms at play. To date, it is still an art to select the proper materials and process parameters to grow desired CNTs.

\section{$7 \quad$ Future plans on the formation of aligned CNTs on the 2D substrate}

Given that the former work has provided some proof

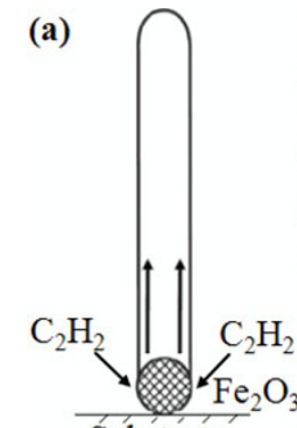

Substrate,

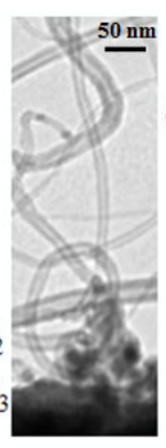

$0 \mathrm{~nm}$

$\mathrm{C}_{2} \mathrm{H}_{2}$

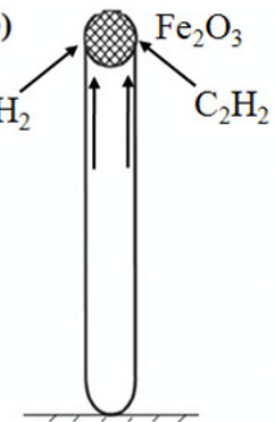

Substrate,
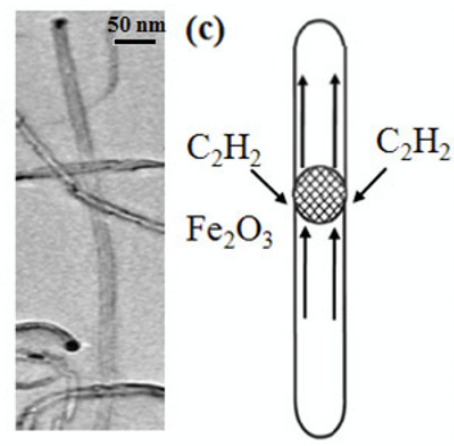

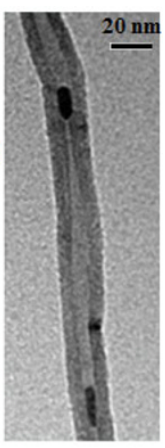

Fig. 14 CNT synthesis mechanisms: (a) base-growth model, (b) tip-growth model, and (c) combination of baseand tip-growth model. 
for the improving effect of zeolite on the synthesis of bulk CNTs, we were wondering if it would have the similar impact on the CNT synthesis on the 2D substrate [87]. Motivated by the previous report [88], we considered using a $2 \mathrm{D}$ assembled monolayer of zeolite crystals instead of non-processing zeolite particles, with the expected result schematically shown in Fig. 15 (right). According to the method reported by Lee et al. [89], a well-aligned monolayer of silicalite-1 microcrystals (AMS) (5.60 $\AA$ ) can be assembled onto a Si wafer, subsequently the catalyst film can be coated on the AMS-coated substrates. With the regular porous structure of the uniformly-oriented zeolite crystals, the catalyst nanoparticles are expected to be stabilized at elevated temperatures and catalyze the synthesis and growth of SWCNTs, schematically shown in Fig. 15(left). Moreover, because of the small-sized pores, the area density of encapsulated catalyst nanoparticles can reach an extent enough for obtaining vertically-aligned CNT arrays on the $2 \mathrm{D}$ substrate. As known, the high order of SWCNT alignments can improve the performance of many CNT-based devices.

\section{Existing challenges and concluding remarks}

Despite plenty of achievements till now on CNTs, including the research on their impressive properties and many devices developed based on them, the fabrication still remains the key obstacle to make CNTs a commercial reality. This may be caused by the complexity generated from the interrelated influences of many parameters involved during CVD of CNTs. Each synthesis requires a careful and rational analysis of the properties of: (1) catalyst and buffer layer materials; (2) the gases used; (3) pretreatment on source gases; (4) the temperatures of the gases and the substrate; and a lot of other effects such as outer forces (magnetic potential). All of them raise several challenges, including: (1) synthesis of SWCNTs of a given diameter; (2) exact chirality control; (3) control of the number of MWCNT walls; (4) growth of isolated CNTs; (5) which is the determining steps in CNT nucleation and growth; and many others [80].

Although there are still a lot of challenges and unexpected problems, there is a hope for commercialization, as many of them have emerged in recent years. Many mechanisms have been identified through some ingenious experiments and sophisticated in situ and ex situ characterizations. Also, new CVD reactors have been developed enabling addition mechanistic studies. Although a unified theory of CNT growth is still not achieved, additional studies of the interactions between gases, catalysts and buffer layers based on existing established principles and coupled with sophisticated characterization equipment may pave the way to a more complete understanding of the growth mechanisms.

\section{Acknowledgement}

This research was supported by the National Research Foundation of Korea (NRF) grant funded by the Korea government (MEST) and by a grant from the 2012 Fundamental R\&D Program of Hanseo University, Korea.

\section{References}

[1] Tans SJ, Verschueren ARM, Dekker C. Roomtemperature transistor based on a single carbon nanotube. Nature 1998, 393: 49-52.

[2] Reibold M, Paufler P, Levin AA, et al. Materials: Carbon nanotubes in an ancient Damascus saber.
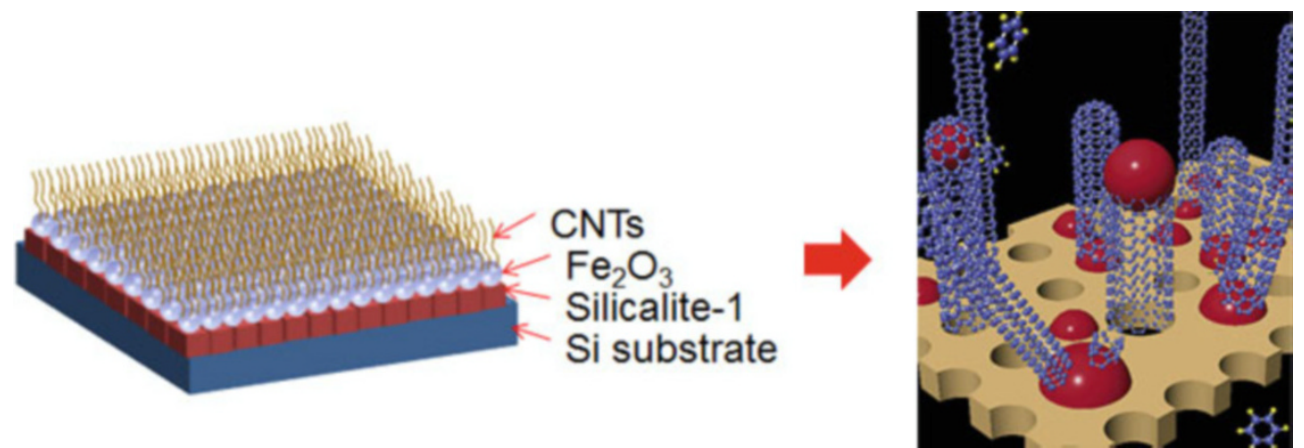

Fig. 15 Schematic image of the structure of the catalyst for CNT synthesis in our work (left), and growth of CNTs from the catalyst nanoparticles trapped into the pores of zeolite (reprinted with permission [88]. Copyright (2003) American Chemical Society.) (right). 
Nature 2006, 444: 286-286.

[3] Hughes TV, Chambers CR. Manufacture of Carbon Filaments. USA patent No. 405 480, 1889.

[4] Oberlin A, Endo M, Koyama T. Filamentous growth of carbon through benzene decomposition. J Cryst Growth 1976, 32: 335-349.

[5] Iijima S. Helical microtubules of graphitic carbon. Nature 1991, 354: 56-58.

[6] Bethune DS, Kiang $\mathrm{CH}$, Devries MS, et al. Cobalt-catalysed growth of carbon nanotubes with single-atomic-layer walls. Nature1993, 363: 605-607.

[7] Iijima S, Ichihashi T. Single-shell carbon nanotubes of 1-nm diameter. Nature 1993, 363: 603-605.

[8] Kroto HW, Heath JR, Brian SCO, et al. $\mathrm{C}_{60}$ : buckminsterfullerene. Nature 1985, 318: 162-163.

[9] Graham AP, Duesberg GS, Hoenlein W, et al. How do carbon nanotubes fit into the semiconductor roadmap? Appl Phys A: Mater Sci Process 2005, 80: 1141-1151.

[10] Saito R, Dresselhaus G, Dresselhaus MS. Physical Properties of Carbon Nanotubes. London: Imperial College Press, 1998.

[11] Nessim GD. Properties, synthesis, and growth mechanisms of carbon nanotubes with special focus on thermal chemical vapor deposition. Nanoscale 2010, 2: 1306-1323.

[12] Xu Z, Bai XD, Wang ZL, et al. Multiwall carbon nanotubes made of monochirality graphite shells. $J$ Am Chem Soc2006, 128: 1052-1053.

[13] Zhu HW, Xu CL, Wu DH, et al. Direct synthesis of long single-walled carbon nanotube strands. Science 2002, 296: 884-886.

[14] Kataura H, Kumazawa Y, Maniwa Y, et al. Optical properties of single-wall carbon nanotubes. Synth Met 1999, 103: 2555-2558.

[15] Yu CH, Shi L, Yao Z, et al. Thermal conductance and thermopower of an individual single-wall carbon nanotube," Nano. Lett 2005, 5: 1842-1846.

[16] Collins PG, Zettle A, Bando H, et al. Nanotube nanodevice. Science 1997, 278: 100-102.

[17] Nihei M, Kawabata A, Kondo D, et al. Electrical properties of carbon nanotube bundles for future via interconnects. Jpn J Appl Phys 2005, 44: 1626-1628.

[18] Baughman RH, Cui CX., Zakhidov AA, et al. Carbon nanotube actuators. Science 1999, 284: 1340-1344.

[19] Liu C, Fan YY, Liu M, et al. Hydrogen storage in single-walled carbon nanotubes at room temperature. Science 1999, 286: 1127-1129.

[20] Liu C, Tong Y, Cheng HM, et al. Field emission properties of macroscopic single-walled carbon nanotube strands. Appl Phys Lett 2005, 86: 223114(1-2).

[21] Avouris P. Molecular electronics with carbon naontubes. Acc Chem Res 2002, 35: 1026-1034.

[22] Carlo AD, Pecchia A, Petrolati E, et al. In: Nanomodeling II, SPIE, San Diego, USA, 2006.

[23] Naeemi A, Meindl JD. Design and performance modeling for single-walled carbon nanotubes as local, semiglobal, and global interconnects in gigascale integrated systems. IEEE Trans Electron Dev 2007, 54: 26-37.

[24] Kong J, Yenilmez E, Tombler TW, et al. Quantum interference and ballistic transmission in nanotube electron waveguides. Phys Rev Lett 2001, 87: 765-775.

[25] Zhou CW, Kong J, Dai HJ. Electrical measurements of individual semiconducting single-walled carbon nanotubes of various diameters. Appl Phys Lett 2000, 76: 1597-1599.

[26] Yokoyama D, Iwasaki T, Ishimaru K, et al. Electrical properties of carbon nanotubes grown at a low temperature for use as interconnects. Jpn J Appl Phys 2008, 47: 1985-1990.

[27] Javey A, Guo J, Wang Q, et al. Ballistic carbon nanotube field-effect transistors. Nature 2003, 424: 654-657.

[28] Collins PC, Arnold MS, Avouris P. Engineering carbon nanotubes and nanotube circuits using electrical breakdown. Science 2001, 292: 706-709.

[29] Frank S, Poncharal P, Wang ZL, et al. Carbon nanotube quantum resistors. Science 1998, 280: 1744-1746.

[30] Naeemi A, Meindl JD. Compact physical models for multiwall carbon nanotube interconnect. IEEE Electron Device Lett 2006, 27: 338-340.

[31] Li HJ, Lu WG, Li JJ, et al. Multichannel ballistic transport in multiwall carbon nanotubes. Phys Rev Lett 2005, 95: 873-879.

[32] Lu JP. Elastic properties of carbon nanotubes and nanoropes. Phys Rev Lett 1997, 79: 1297-1300.

[33] Salvetat JP, Bonard JM, Thomson NH, et al. Mechanical properties of carbon nanotubes. Appl Phys A: Mater Sci Process 1999, 69: 255-260.

[34] Yu MF, Files BS, Arepalli S, et al. Tensile loading of ropes of single wall carbon nanotubes and their mechanical properties. Phys Rev Lett 2000, 84: 5552-5555.

[35] Krishnan A, Dujardin E, Ebbesen TW, et al. Young's modulus of single-walled nanotubes. Phys Rev B: Condens Matter 1998, 58: 14013-14019.

[36] Zhou G, Duan W, Gu B. First-principles study on morphology and mechanical properties of 
single-walled carbon nanotubes. Chem Phys Lett 2001, 333: 344-349.

[37] Yao Z, Zhu CC, Cheng M, et al. Mechanical properties of carbon nanotube by molecular dynamics simulation. Comput Mater Sci 2001, 22: 180-184.

[38] Demczyk BG., Wang YM, Cumings J, et al. Direct mechanical measurement of the tensile strength and elastic modulus of multiwalled carbon nanotubes. Mater Sci Eng A 2002, 334: 173-178.

[39] Hone J, Whitney M, Zettl A. Thermal conductivity of single-walled carbon nanotubes. Synth Met 1999, 103: 2498-2499.

[40] Pop E, Mann D, Wang Q, et al. Thermal conductance of an individual single-wall carbon nanotube above room temperature. Nano Lett 2006, 6: 96-100.

[41] Kim P, Shi L, Majumdar A, et al. Thermal transport measurements of individual multiwalled nanotubes. Phys Rev Lett 2001, 87: 215502.

[42] Fowler RH, Nordheim L. Electron emission in intense electric fields. Proc R Soc London Ser A 1928, 119: 173-181.

[43] Fan SS, Chapline MG, Franklin NR, et al. Self-oriented regular arrays of carbon nanotubes and their field emission properties. Science 1999, 283: 512-514.

[44] Zhu HW, Wei JQ, Wang KL, et al. Applications of carbon materials in photovoltaic solar cells. Solar Eng Mater Solar Cells 2009, 93: 1461-1470.

[45] Carbon Nanotubes in Photovoltaics. From Wikipedia.

[46] Kymakis E, Alexandrou I, Amaratunga GAJ. High open-circuit voltage photovoltaic devices from carbon-nanotube-polymer composites. Prog in Photovoltaics: Res Appl 2003, 93: 1764-1768.

[47] Kongkanand A, Dominguez RM, Kama PV. Single wall carbon nanotube scaffolds for photoelectrochemical solar cells. Capture and transport of photogenerated electrons. Nano Lett 2007, 7: 676-680.

[48] Kratschmer W, Lamb LD, Fostiropoulos K, et al. Solid C60: A new form of carbon. Nature 1990, 347: 354-358.

[49] Yakobson BI, Smalley RE. Fullerene nanotubes: $\mathrm{C}_{1,000,000}$ and beyond. Am Sci 1997, 85: 324-337.

[50] Guo T, Nikolaev P, Thess A, et al. Catalytic growth of single-walled nanotubes by laser vaporization. Chem Phys Lett 1995, 243: 49-54.

[51] Zhao W, Seo DN, Kim HT, et al. Characterization of multi-walled carbon nanotubes (MWNTs) synthesized by CCVD using zeolite template from acetylene. J Ceram Soc Jpn 2010, 118: 983-988.
[52] De Jong KP, Geus JW. Carbon nanofibers: Catalytic synthesis and application. Catal Rev Sci Eng 2000, 42: 481-510.

[53] Kong J, Cassell AM, Dai HJ. Chemical vapor deposition of methane for single-walled carbon nanotubes. Chem Phys Lett 1998, 292: 567-574.

[54] Hafner JH, Bronikowski MJ, Azomian BR., et al. Catalytic growth of single-wall carbon nanotubes from metal particles. Chem Phys Lett 1998, 296: 195-202.

[55] Ajayan PM. Nanotubes from carbon. Chem Rev 1999, 99: 1787-1789.

[56] Cinke M, Li J, Chen B, et al. Pore structure of raw and purified HiPco single-walled carbon nanotubes. Chem Phys Lett 2002, 365: 69-74.

[57] Yao Z, Kane CL, Dekker C. High-field electrical transport in single-wall carbon nanotubes. Phys Rev Lett 2000, 84: 2941-2944.

[58] Hone J, Whitney M, Piskoti C, et al. Thermal conductivity of single-walled carbon nanotubes. Phys Rev B 1999, 59: R2514-2516.

[59] Niyogi S, Hamon MA, Hu H, et al. Chemistry of single-walled carbon nanotubes. Acc Chem Res 2002, 35: 1105-1113.

[60] Thosterson ET, Li C, Chou TW. Nanocomposites in context. Compos Sci Technol 2005, 65: 491-516.

[61] Ouyang M, Huang JL, Lieber CM. Fundamental electronic properties and applications of single-walled carbon nanotubes. Acc Chem Res 2002, 35: 1018-1025.

[62] de Heer WA, Chatelain A, Ugarte D. A carbon nanotube field-emission electron source. Science 1995, 270: 1179-1180.

[63] Bonard JM, Salvetat JP, Stockli T, et al. Field emission from single-wall carbon nanotube films. Appl Phys Lett 1998, 73: 918-920.

[64] Ago H, Imamura S, Okazaki T, et al. CVD growth of single-walled carbon nanotubes with narrow diameter distribution over $\mathrm{Fe} / \mathrm{MgO}$ catalyst and their fluorescence spectroscopy. J Phys Chem B 2005, 109: 10035-10041.

[65] Hata K, Futaba DN, Mizuno K, et al. Water-assisted highly efficient synthesis of impurity-free single-walled carbon nanotubes. Science 2004, 306: 1362-1364.

[66] Andews R, Jacques D, Rao AM, et al. Continuous production of aligned carbon nanotubes: A step closer to commercial realization. Chem Phys Lett 1999, 303: 467-474.

[67] Kitiyanan B, Alvarez WE, Harwell JH, et al. Controlled production of single-wall carbon nanotubes by catalytic decomposition of $\mathrm{CO}$ on 
bimetallic Co-Mo catalysts. Chem Phys Lett 2000, 317: 497-503.

[68] Ding D, Wang J, Cao Z, et al. Synthesis of carbon

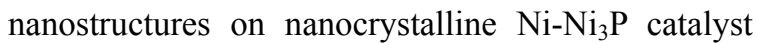
supported by $\mathrm{SiC}$ whiskers. Carbon 2003, 41: 579-582.

[69] Cheung CL, Kurtz A, Park H, et al. Diameter controlled synthesis of carbon nanotubes. $J$ Phys Chem B 2002, 106: 2429-2433.

[70] Willems I, Konya Z, Colomer Jf, et al. Control of outer diameter of thin carbon nanotubes synthesized by catalytic decomposition of hydrocarbons. Chem Phys Lett 2000, 317: 71-76.

[71] Kumar M, Ando Y. Controlling the diameter distribution of carbon nanotubes grown from camphor on a zeolite support. Carbon 2005, 43: 533-540.

[72] Ward J, Wei BQ, Ajayan PM. Substrate effects on the growth of carbon nanotubes by thermal decomposition of methane. Chem Phys Lett 2003, 376: 717-725.

[73] Karthik M, Vinu A, Tripathi AK, et al. Synthesis, characterizationand catalytic performance of $\mathrm{Mg}$ and Co substituted mesoporous aluminophosphates. Micropor Mesopor Mater 2004, 70: 15-25.

[74] Lee HJ, Kim YM, Kweon OS, et al. Structural and morphological transformation of $\mathrm{NaX}$ zeolite crystals at high temperature. J Eur Ceram Soc 2007, 27: 561-564.

[75] Kim IJ, Zhao W, Fan X, et al. Effect of the TEOS/Al(i-pro) ${ }_{3}$ mol ratio in the composition on the crystal morphology of zeolites. J Ceram Res Proc 2010, 11: 158-163.

[76] Zhao W, Lee MJ, Kim HT, et al. The synthesis of carbon nanotubes (CNTs) by catalytic CVD using $\mathrm{Fe} / \mathrm{Co}$-supported zeolite template. Electr Mater Lett 2011, 7: 139-144.

[77] Zhao W, Seo DN, Kim HS, et al. Carbon nanotubes synthesized by catalytic chemical vapour deposition using Fe-supported zeolite. Asian J Chem 2011, 23: 2314-2318.

[78] Hernadi K, Fonseca A, Nagy JB, et al. Catalytic synthesis of carbon nanotubes using zeolite support.
Zeolites 1996, 17: 416-423.

[79] Fonseca A, Hernadi K, Nagy JB, et al. Optimization of catalytic production and purification of buckytubes. J Mol Catal A 1996, 107: 159-168.

[80] Harutyunyan AR. Chemical vapor deposition of carbon nanotubes: A review on growth mechanism and mass production. $J$ Nanosci Nanotechnol 2009, 9: 2480.

[81] Zhao W, Lee MJ, Kim HT, et al. Formation of multi-walled carbon nanotubes by catalytic chemical vapour deposition using zeolite encapsulated nanocrystalline cobalt oxides. Asian J Chem 2011, 23: 5457-5460.

[82] Zhao W, Kim HS, Kim HT, et al. Synthesis and growth of multi-walled carbon nanotubes (MWNTs) by CCVD using Fe-supported zeolite templates. $J$ Ceram Proc Res 2011, 12: 392-397.

[83] Wagner RS, Ellis WC. Vapor-liquid-solid mechanism of single crystal growth. Appl Phys Lett 1964, 4: 89-90.

[84] Meyyappan M. Carbon Nanotubes Science and Application. CRC Press LLC, 2005: 110-116.

[85] Trianatafyllidis KS, Karakoulia SA, Gournis D, et al. Formation of carbon nanotubes on iron/cobalt oxides supported on zeolite-Y: Effect of zeolite textural properties and particles morphology. Micropourous Mesoporous Mater 2008, 110: 128-140.

[86] Behr MJ, Mkhoyan KA, Aydil ES. Orientation and morphological evolution of catalyst nanoparticles during carbon nanotube growth. ACS Nano 2010, 4: 5087-5094.

[87] Zhao W, Kim HS, Seo DN, et al. Assembled monolayer of silicalite-1-supported iron oxide nanoparticles for carbon nanotube growth by catalytic CVD (CCVD). Asian J Chem 2012, accepted.

[88] Hayashi T, Kim YA, Matoba T, et al. Smallest freestanding single-walled carbon nanotube. Nano Lett 2003, 3: 887-889.

[89] Lee JS, Kim JH, Lee YJ, et al. Manual assembly of microcrystal monolayers on substrates. Angew Chem Int Ed 2007, 46: 3087-3090. 